\title{
试论小学体育教学中学生安全教育的探索
}

赵喜

宁夏回族自治区中卫市沙坡头区常乐镇水车小学

DOI:10.32629/er.v3i1.2328

[摘要] 近年来,我国关于小学体育安全事故的报道层出不穷,小学体育安全问题也被推到了风暴的中心,体育安全成为一个热点问题。小学体 育课堂的教育安全是教师需要关注的重点。由于体育教育的特殊性,户外教学科目较多, 课堂上容易出现一些安全问题, 如: 自由活动过于激烈, 运动器材存在隐患, 安全教育不重视等。消除这些体育教学中的安全隐患是保证体育教育顺利进行的前提。小学体育作为小学教育的教学过程 中更应重视小学生的安全教育。只有足够重视小学生体育课堂的安全教学问题,并对其实施有效措施, 从而避免安全问题的发生。这才能有效的 开展小学生体育教学活动,最大限度减少体育教学的安全威胁。为此, 提出了解决这些安全问题的对策。

[关键词] 小学体育; 学生安全; 教育; 探索

随着我国新课程改革的不断推进和时代的发展, 在全面实施素质教育 的今天, 学校和家长都开始关注小学生的身体素质。重视体育教育, 既要提 高学生的学习能力, 又要提高学生的身体素质。学生安全教育在体育教学 中发挥着越来越重要的作用。安全开展体育活动是增强体育教育意义的前 提。阐述了小学体育安全问题产生的原因。然而, 从目前的体育教学情况 看来, 小学生安全教育还存在着许多问题。通过将安全教育融入小学生安 全教学现状, 建立以体育为平台, 融合其他教学手段的安全教学模式。实施 有效的应对策略, 可以促进小学体育的现代化。

1 小学体育教学中安全问题的成因

1. 1 师生安全意识不足

体育教学与文化教学有很大的不同, 教师和学生都需要以体育的形 式参与课堂活动。教师安全意识的缺乏和对学生课堂保护监督不到位是 造成小学体育课堂安全问题的重要原因之一。一些教师没有认识到小学 生缺乏自我保护能力和年龄特征, 没有积极地进行保护。最终影响体育 教育的安全。

1.2 体育课前热身活动不足

因为体育教学活动具有一定的特殊性, 在真正开始体育教学之前, 教师需要正确引导学生进行课前热身活动, 有效的课前热身是体育教育 安全的关键。热身活动可以调动身体各个部位的运动功能, 降低发生安 全事故的风险。但是有些小学体育老师对课前热身活动并不重视, 只是 走马观花一般引导学生扭动手脚关节, 这不能有效的对学生起到课前热 身意义。这种单纯课前热身的形式, 不仅使课堂失去活力, 也违背了体育 教学的初衰。

1. 3运动设备检修不足

前巧设情境, 激发学生的学习动机; 在教学过程中, 给予不断地鼓励, 帮助 学生获得成功; 在活动结束时, 注重运用激励性评价, 鼓励学生进行创造性 学习, 评价中又注意引导学生评估优点, 往好处看, 从而强化学生主动参与 学习的情感和动机。另外, 在课堂上自始至终都在使用激励性的教学语言, 积极主动地寻找学生的闪光点给予激励, 这种做法所体现的教学思想就是 教师要主动走到每个学生身边, 认识到每个学生都是生命的主体。学生一 旦感到自己被老师关注和认可, 就会出现主动乐学的情景, 这种情景下进 行教学, 就会取得意想不到的良好的教学效果。

\section{4 结语}

随着新课程改革的深入发展, 小学数学教学越来越强调要调整教学模 式和教学方法, 以期充分调动学生的学习兴趣, 提高学生的学习效率。数学
体育器材的老化和损坏会增加小学体育安全事故发生的概率。小学体 育教学活动通常在课后进行, 教师和学生需要借助体育器材感受体育的兴 趣。在体育教育的低地位下, 许多学校忽视了体育器材的维护。有些设备 太旧了, 不能用, 但仍在使用。体育器材的保养不足, 大大增加了体育教学 过程中的安全隐患问题。

\section{2 小学体育课安全问题规避策略}

为了及时避免小学体育教育的安全问题, 学校、教师和学生需要共同 寻找安全隐患, 解决安全问题。小学体育安全问题规避策略如下:

2. 1 提高师生安全意识

只有体育老师带领学生树立良好的安全意识, 才能有效形成安全的 体育教学氛围, 从而才能有效促进小学体育教学中安全问题的避免。教 师作为教学的领导者, 应树立强烈的安全意识, 观察威胁学生安全的事 物和现象, 引导学生树立安全运动意识。教师应组织学生注意体育课堂 纪律。小学生活泼好动, 自我控制能力有限, 很喜欢和其他同学一起参加 体育活动。要发现这些问题, 体育教师应该在第一时间停止, 并向学生解 释停止的原因, 让小学生意识到他们的娱乐形式存有安全隐患。在小学 体育课上, 老师可以把学生平均分成小组或自愿竭诚小组, 让小组成员 轮流担任组长, 让学生有意识的注重安全。随着时间的推移, 小学生将建 立一种安全感。

\section{2 做好协调分组活动}

在体育课课堂上, 科学管理课堂纪律, 保证学生安全, 集体行动是必然 的选择。首先, 可以选择一个组长来管理每个小组的学生, 这样可以减轻老 师的负担, 使运动更有组织性。例如, 一些学生, 因为他们不想去上体育课, 上课铃响后, 会在操场的铁栅栏, 跑到校园外的地方玩, 分组可以有效地减

学习对学生来说, 是学习的起点, 数学是一直陪伴他们成长的学科, 教师在 小学阶段一定要注意培养学生学习数学的兴趣和信心, 通过多样的方式创 设充满趣味的小学数学课堂, 提高小学生对数学学习的兴趣, 为今后的学 习打下基础。

\section{[参考文献]}

[1]陶妮. 趣味教学法在小学数学教学实践中的应用[J]. 中国农村教 育,2019(12):89.

[2]曾美容. 趣味教学法在小学数学教学实践中的应用[J]. 数学学习与 研究,2018(17):75.

[3]王焕之.趣味教学法在小学科学教学中的应用 [J]. 课程教育研 究,2017(02):162-163. 
少这种情况的发生。第二, 如果课堂上需要运动器材, 可以将学生分组, 减 少单独行动的机会, 避免不必要的紧急情况。体育课程内容不仅应该课外 小游戏, 它的目的不仅是运动, 但也应该设计一些户外安全知识小练习, 例 如, 一个学生不小心把他的手腕运动, 看如何处理, 但这些也可以用作点缀 着有趣的小体育活动。

2. 3优化体育课热身活动

热身是所有运动的前提。对于小学生来说, 心理发育不完全, 自身的安 全隐患意识相当淡薄, 对课前热身无意识。并且小学还是能活泼好动, 上体 育课及其兴奋的玩要, 肆无忌惮的追逐奔跑, 各个细胞都处于极度兴奋过 的状态, 这一来更容易产生腿部和脚部抽筋摔伤等安全问题。且由于小学 生正处于成长期。他们的身体机能远不如成年人, 所以热身活动尤为重要。 热身活动可以促进肢体的运动, 放松肌肉, 灵活关节, 提高小学生身体承受 运动的能力。从而避免体育课堂中存在的安全问题, 教师应选择符合小学 生身心特点的热身形式进行教学, 既能增加课堂教学活动的趣味性, 又能 减少体育教学中的安全隐患。这时, 教师应集中注意力, 积极做好指导工作, 带领学生做暖身活动, 如做一整套广播体操或慢速绕圈跑活动。或者体育 老师可以改变以往的二审活动, 可以组织学生创作出属于他们班级特点的 热身活动方式, 还可以投票选择背景音乐, 让孩子们在兴趣中找热身活动, 从而提高学生对热身的兴趣。既保证了体育教学安全, 有提高了学生学习 的积极性。

\section{4做好运动器材的定期检查工作}

每个学校的操场都或多或少会有一些固定的室外健身器材, 这些运动 器材的质量与完好状态, 直接影响着体育课堂教学的安全性。教师需要借 助体育设备去完成教学内容的展示, 如果在体育课上老师需要用到这类室 外器材, 必须要在课前做好相应的检查, 确保运动器材的安全性。做好体育 设备的检修工作, 以提高体育课堂活动的安全性。例如, 单双杜这类长期固 定在室外的运动器材, 经过长时间的风雨打击, 和长时间晃动, 便会间接造 成其支架不稳定, 所以对学生的安全也带来了直接的危险。小学管理者应 指派专人对体育器材进行维护, 并在每次使用前后进行安全维护工作, 以 保证学生能够安全使用体育器材, 学习体育技能。体育教师还应在课堂教 学过程中随时观察体育器材, 发现问题及时向有关人员报告。教育学生正 确使用体育设施, 减少教室安全隐患, 正确使用学生是最有效、最有教育意 义的。

\section{3 安全教育与体育教育相融合}

安全教育是体育教育组成的基本, 其体育教育和安全教育是紧密相 连。安全教育的目的就是为了让学生掌握体育和保健的基本知识, 提高体
育技术水平。他可以分为两个部分：课堂教学和课外体育活动。体育老师 可以根据体育教学课程的特点, 设计有趣的教学环节, 科学有效的将安全 教育和小学体育教育想融合。

3. 1 课堂教育

物理教育的课堂教学主要在课堂上, 教学重点主要是理论知识, 根 据这部分的教学中, 教师应注重教学设计的过程中, 让学生意识到危险, 知道要学会避免危险和如何寻求帮助, 从而进行实践教学环节为以下奠 定基础。

3. 2 体育活动

3.2.1危险场景的撤离

在教学过程中, 教师应结合体育教学的特点, 和体育教学的功能, 在教 学设计中加入安全从教学技能的培养, 如培养学生在跑、跳、攀爬等运动 中需要注意的问题, 使学生在紧急情况下可以迅速离开, 或是在此种危急 情况下有效的进行安全操作。

3.2.2简单伤势的处理

学生通过学习安全教育的知识, 从而有效避免运动伤害发生后的第二 次伤害。具体情况包括运动时摔倒出血的控制和扭伤的及时处理。老师可 以在体育教学时进行课前教学, 在这种情况发生时及时治疗。并且教师要 明确的告知学生, 如果在伤势严重, 自身无法处理的情况下, 要积极求救, 等待医护的到来。

\section{4 结语}

根据本文所述, 小学生的身体还正处于发育阶段, 所以在体育教学过 程中对小学生安全教育工作是一个长期的过程, 教学老师应该在第一时间 认识到体育安全的重要性, 在体育教学过程中, 要结合学生活泼好动的特 点设置教学环节有效将安全教育知识传递给学生, 让学生在注重安全意识, 从而给学生创造一个安全的教学环境。并且体育老师在体育教学活动的过 程中一定要安全监管学生, 让学生在安全的基础上进行体育教育课程。

\section{[参考文献]}

[1]马科栋.试论小学体育教学中学生安全教育的探索[J].中国校外教 育,2019(22): $7+2$.

[2]陈振宇.小学体育教学中的安全教育策略的探究[J].小学生作文辅 导:读写双赢,2018(10):93.

[3]高渊.关于小学体育教学中安全教育的几点思考[J].科普童话:新课 堂,2017(4):53.

[4] 邓生剑. 安全教育在小学体育教学中的融合 [J]. 新课程 (上),2017(3):222. 